\title{
OBSERVAÇÃO EXPERIENCIAL DA ENSEADA DE BOTAFOGO, RIO DE JANEIRO 1
}

\author{
RHEINGANTZ, Paulo Afonso
}

Doutor, Arquiteto, Professor da FAU/UFRJ. E-mail par@ufri.br

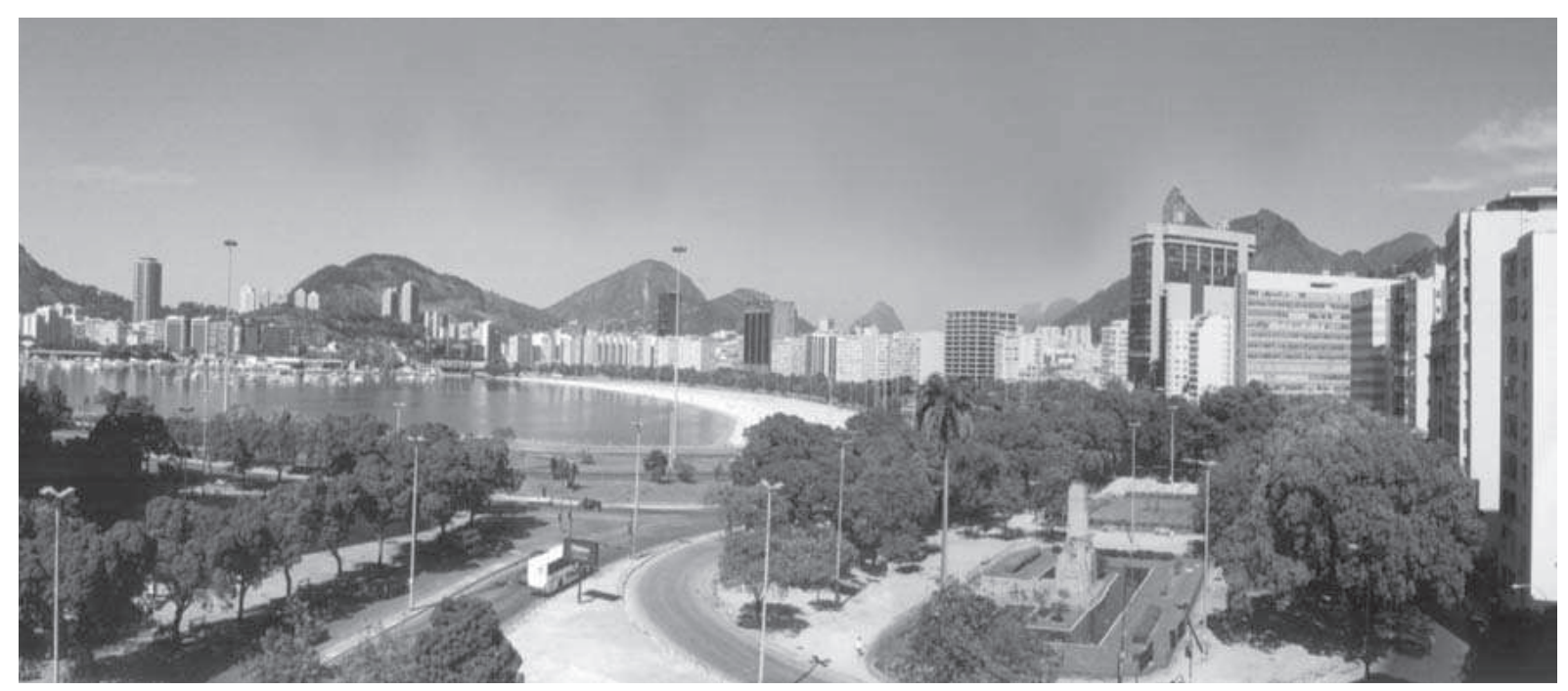

Figura 1: Vista da Enseada de Botafogo (1999)

Fonte: RHEINGANTZ, 2000, p. 14

"O desprezo pela natureza foi tão grande que nem as montanhas escaparam e a linha barroca e magnífica que as ligava ficou perdida entre os prédios próximos delas construídos. E os passeios, os pontos pitorescos, os panoramas esplêndidos que ofereciam, fracionaram-se entre os altos edifícios que o Carlos Lacerda, num dia de confraternização imobiliária, resolveu aprovar" (NIEMEYER 1980: 38-40);

\section{RESUMO}

Observação Incorporada da Enseada de Botafogo, Rio de Janeiro

Inspirado no esgotamento do paradigma da racionalidade que cunhou toda a trajetória da ciência nos três últimos séculos, e em autores que buscam resgatar a presença (e a prevalência) dos valores humanos na ciência, escrevi este artigo como uma provocação, inspirado nas impressões e análises produzidas ao longo de uma década de experiência como morador da Enseada de Botafogo, Rio de Janeiro. Baseado no pressuposto de Humberto Maturana e Francisco Varela - "viver é conhecer" -, amparado pelo argumento de Boaventura Santos, Fritjof Capra e Illia Prigogine \& Isabelle Stengers e utilizando como instrumento de análise a observação incorporada, descrevo o contexto urbano observado com a intenção de questionar a lógica ainda prevalente sobre a produção do ambiente construído e apresento um cenário digno de um filme de ficção científica, não fossem suas causas e atos tão reais e concretos.

\section{Palavras-chave: Observação, ambiente, lugar experiência, Botafogo.}

\section{ABSTRACT}

Embodied Observation of the Enseada de Botafogo, Rio de Janeiro/Brazil

This article was inspired by the depletion of the rationality paradigm which has minted all the path of the science in the last three centuries as well as in authors that try to redeem the presence of human values in the science. I decided to write it as provocation after my impressions and analysis developed during a decade as a resident of the enseada de Botafogo, Rio de Janeiro. Base on the presupposition of Humberto Maturana and Francisco Varela - "to live is to know" - supported by the arguments of Boaventura Santos, Fritjof Capra e Illia Prigogine \& Isabelle Stengers in which the scientific knowledge should get closer again to the common sense, using as an analysis tool, the embodied observation, I describe the observed urban 
context with the aim of questioning the prevailed logic of the constructed environment and I describe a film set proper of a science fiction film if it was not for its causes and acts so real and feasible.

\section{Key words: Observation, environment, place, experience, Botafogo.}

\section{Introdução e bases teóricas}

Diferentemente da visão de mundo fundada na noção de um universo orgânico, vivo e espiritual, a "Revolução Científica" dos século XVI e XVII propõe uma nova visão, também conhecida como cosmovisão cartesiana, que considera a Terra matéria inerte a ser explorada e manipulada e o ambiente construído, um "mundo morto", inanimado, fragmentado, que pode ser estudado e manipulado para os propósitos humanos.

Acreditando na crença de Bacon, de que poderia "forçar a natureza a revelar os seus segredos ao homem", o homem desenvolve um poderoso método "reducionista" de investigação e a ciência passa a oferecer ao homem um mundo morto no qual "extinguem-se a visão, o som, o sabor, o tato e o olfato, e junto com eles vão-se também as sensibilidades estética e ética, os valores, a qualidade, a alma, a consciência, o espírito" (Laing in Capra 1991: 34).

O paradigma cartesiano, o capitalismo, a industrialização e a urbanização produzem profundas modificações na dimensão cultural do ambiente e o espaço passa a ter a função de distribuição ordenada dos indivíduos e dos serviços e a nova arquitetura se desenvolve fora dos padrões tradicionais, subvertendo o saber anterior. A qualidade do ambiente construído independe cada vez mais das relações entre cultura e geografia, e o homem entra em uma espécie de "transe" tecnológico e acaba produzindo violenta perda na dimensão cultural da cidade, produto do conhecimento acumulado por sucessivas depurações às diferentes condições climáticas, através da ação solidária e continuada dos seus habitantes.

Partindo desta problemática, neste trabalho procuro estabelecer as bases para uma abordagem capaz de contribuir para superar o equívoco que faz com que as pessoas confundam hábitat "civilizado" com um ambiente construído que se torna cada vez mais despersonalizado e desconfortável.

A cidade do Rio de Janeiro é um bom exemplo deste processo de degradação das tradições culturais da arquitetura e da paisagem natural. Situada em uma baía de beleza exuberante, e marcada pela luta para transformar em planície "as colinas e os vales, avançando sobre os brejos, os mangues e também sobre a montanha e fazendo recuar a linha do litoral" (Bernardes 1995: 82), sua história confirma o desejo de submeter a natureza aos caprichos do homem.

A "fúria urbanística" (Drummond e Bandeira 1965) testemunha "o trânsito perverso de um progresso que fomenta, em nome do moderno, a transformação grosseira e desnecessária da fisionomia da cidade" (Gomes 1994: 94). A julgar pela opinião dos cariocas, que consideram as belezas naturais a maior qualidade da cidade e a praia como seu programa favorito², o Rio de Janeiro está diante de um novo dualismo: o reconhecimento da beleza natural como o maior patrimônio da cidade convive com um processo de verticalização que substitui a paisagem natural por uma paisagem construída "sem alma" e "sem encanto".

Até onde a cidade e sua arquitetura continuarão a reproduzir a "lógica do excesso" da produção econômica que transforma a destruição em seu objetivo - destruir para controlar efetivamente o crescimento e administrar o excedente (Featherstone 1995) - limitando a função do espaço à sua função distributiva e substituindo os limites naturais e culturais do hábitat pelos limites técnicos, econômicos e políticos - tornando seus lugares impessoais, desumanos e frios, mas "civilizados"?

Ao propor seu Paradigma Social - "uma constelação de concepções, de valores, de percepções e de práticas compartilhadas por uma comunidade, que dá forma a uma visão particular 
da realidade" (Capra 1997: 25) - Capra introduz a concepção de "comunidade" e "rede" ao pensamento sistêmico e, ao substituir o termo sistêmico por social, expande os horizontes do conceito de sociedade sustentável e de projeto participativo.

Crítico do conhecimento científico moderno - "um conhecimento desencantado e triste que transforma a natureza num autômato" (B. Santos 1995: 32) -, Boaventura Santos recoloca o pesquisador como sujeito da aventura do conhecimento, ao reconhecer o "caráter autobiográfico" e "auto-referenciável" da ciência, construído através da imaginação pessoal e dos critérios estabelecidos pelo próprio cientista e resgata a interação dialética sujeito/objeto ao reconhecer que o ato e o produto do conhecimento são inseparáveis.

Ilya Prigogine e Isabelle Stengers (1992; 1997) sugerem uma "nova aliança" do homem com a natureza que ele descreve, que busque compartilhar uma visão da ciência, em lugar de uma visão de ciência e que, a exemplo da arte e da filosofia, se transforma em uma experimentação "criadora de questões e de significações".

Humberto Maturana e Francisco Varela (1995), por sua vez, consideram a cognição como "uma atividade contínua de criar um mundo por meio do processo de viver" (Capra 1997: 211): "viver é conhecer" e inclui a percepção, a emoção e o comportamento.

A seguir, procuro retratar a influência do olhar compreensivo do sujeito da criação científica - que é autobiográfica, auto-referencial e não é neutra -, que possibilita ao texto assumir uma postura mais contemplativa, socializadora e subjetiva.

Como procedimento de análise, utilizo a observação incorporada, designação adotada pelo grupo Projeto e Qualidade do Lugar do Programa de Pós-graduação em Arquitetura da FAU/UFRJ, derivada dos passeios à deriva que baseia-se no entendimento de que a realidade é sempre um argumento explicativo, e que "as explicações científicas não fazem referência a realidades independentes do observador" (Maturana 2001: 57) e procura incorporar os relatos de observadores que já possuam uma vivência do lugar impregnada de afetos e significados

\section{A escolha do sítio}

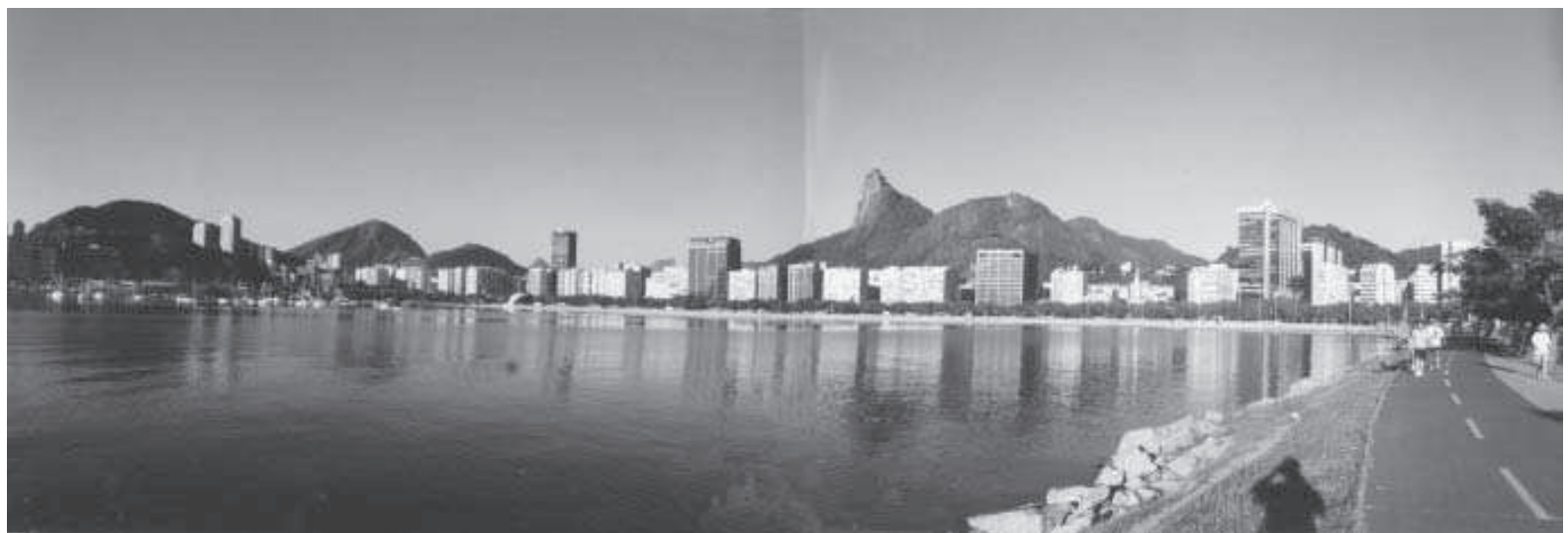

Figura 2: Vista panorâmica da enseada de Botafogo a partir do Morro da Viúva: relação aleatória entre a massa edificada e o perfil natural dos morros, fruto da prevalência da concepção do edifício como obra isolada de arquitetura em detrimento de seu relacionamento com o contexto; arquitetura como protagonista do processo de degradação da paisagem natural.

Diante da impossibilidade de evitar a interferência do observador-sujeito em sua relação com o ambiente construído, e entendendo ser necessário fornecer indícios da minha visão de mundo, procuro compartilhar uma leitura bem pessoal da enseada de Botafogo (Fig. 2), onde residi por dez anos. Para tanto, procuro integrar em um único texto as visões de morador, de cidadão, de arquiteto, de professor de projeto e de pesquisador. 
A escolha do sítio deveu-se a diferentes fatores:

- Como morador - da janela do antigo apartamento é possível contemplar toda a enseada (Fig. 1) - sou parte integrante de sua organização social. A vista e as caminhadas na avenida Beira-mar e na Praia de Botafogo contribuíram para uma experiência topofílica rica de questões e significações que desencadeou mudanças significativas no modo como percebo e me relaciono com o sítio.

- Sua paisagem natural contém os principais elementos característicos da cidade do Rio de Janeiro - presença do mar, da montanha, de baixios alagadiços hoje aterrados, e vegetação - resquícios da Mata Atlântica (Fig. 2).

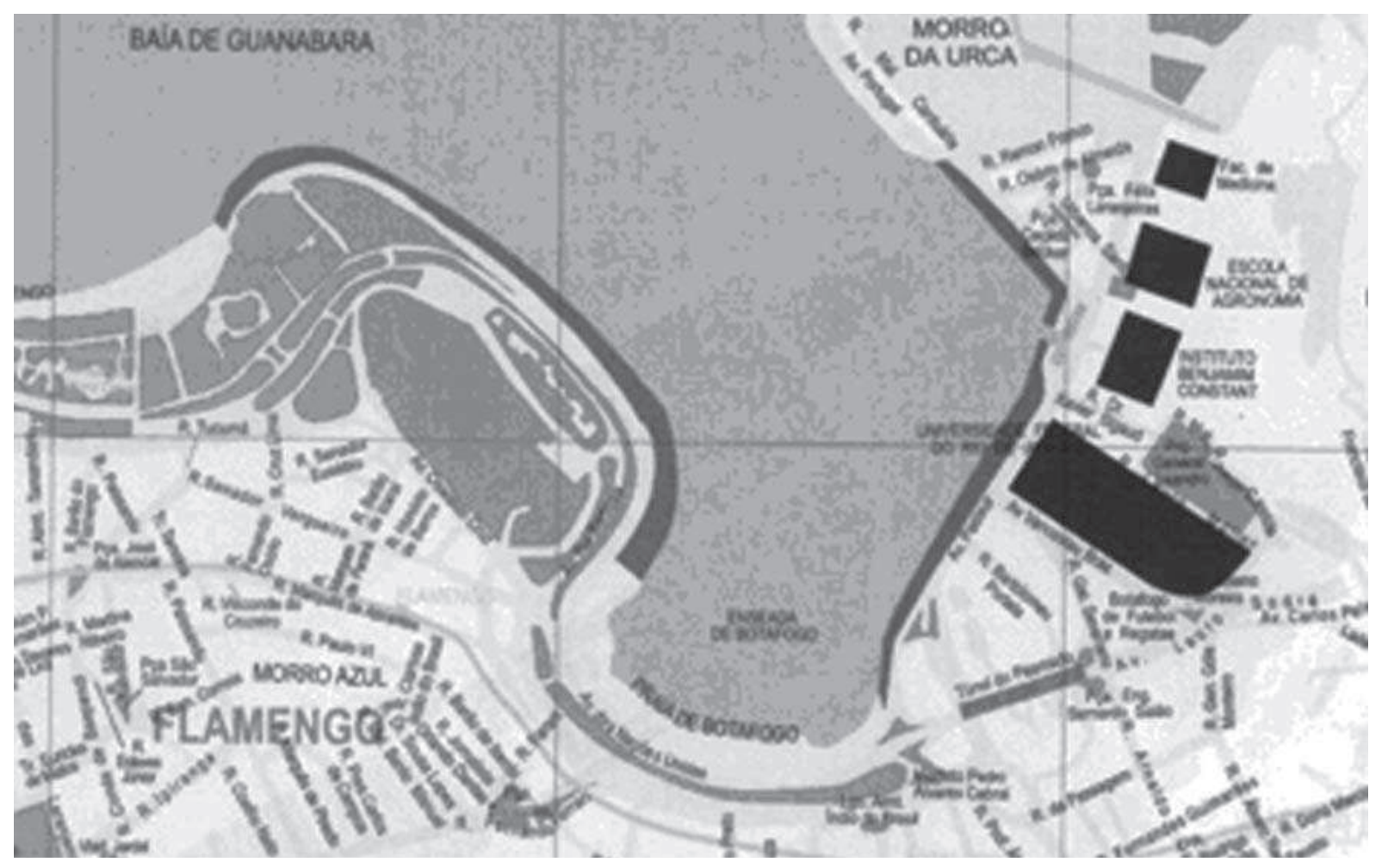

Figura 3: Vista da enseada de Botafogo. As áreas escuras junto do mar indicam os muros e enrocamentos do aterro. As quadras escuras, os edifícios das universidades UFRJ e UNIRIO. As manchas em cinza escuro, o Parque do Flamengo e - Morro da Viúva. Em cinza mais claro, as vias e a linha 1 do metrô

Fonte: Rio Listas 99, Planta 4

- A intervenção humana na paisagem contém diversas características do processo de urbanização da cidade - praia e ar poluídos, morro devastado/modificado por túneis, viadutos e cortes; aterro de áreas alagadiças e praia; engarrafamentos, alagamentos e proximidade do metrô; cenário marcado pela variedade de edifícios, que destoam entre si por suas cores, volumetria, gabarito, partido de implantação, aparência ou pelo uso. (Fig. 4).

- A diversidade de usos que abriga: habitação de luxo, classe média e popular; shopping-center, edifícios de escritórios/corporativos, bancos, hospitais, cinemas, igreja, bares e restaurantes, escolas, universidades, parque e proximidade com favela (Morro Azul).

- A diversidade de grupos humanos que habitam ou freqüentam o local (moradores, trabalhadores, usuários, passageiros e turistas): convívio do "luxo" com o "lixo" (moradores de rua e de alguns edifícios "pouco recomendáveis"); presença de idosos e crianças; ocorrência de assaltos e roubos de automóveis.

- Seu poder de atração, evidenciado pela presença de alguns dos mais modernos edifícios de escritórios abrigando importantes organizações - FGV, Coca-Cola, Telemar, Telefônica, IBM, etc. 


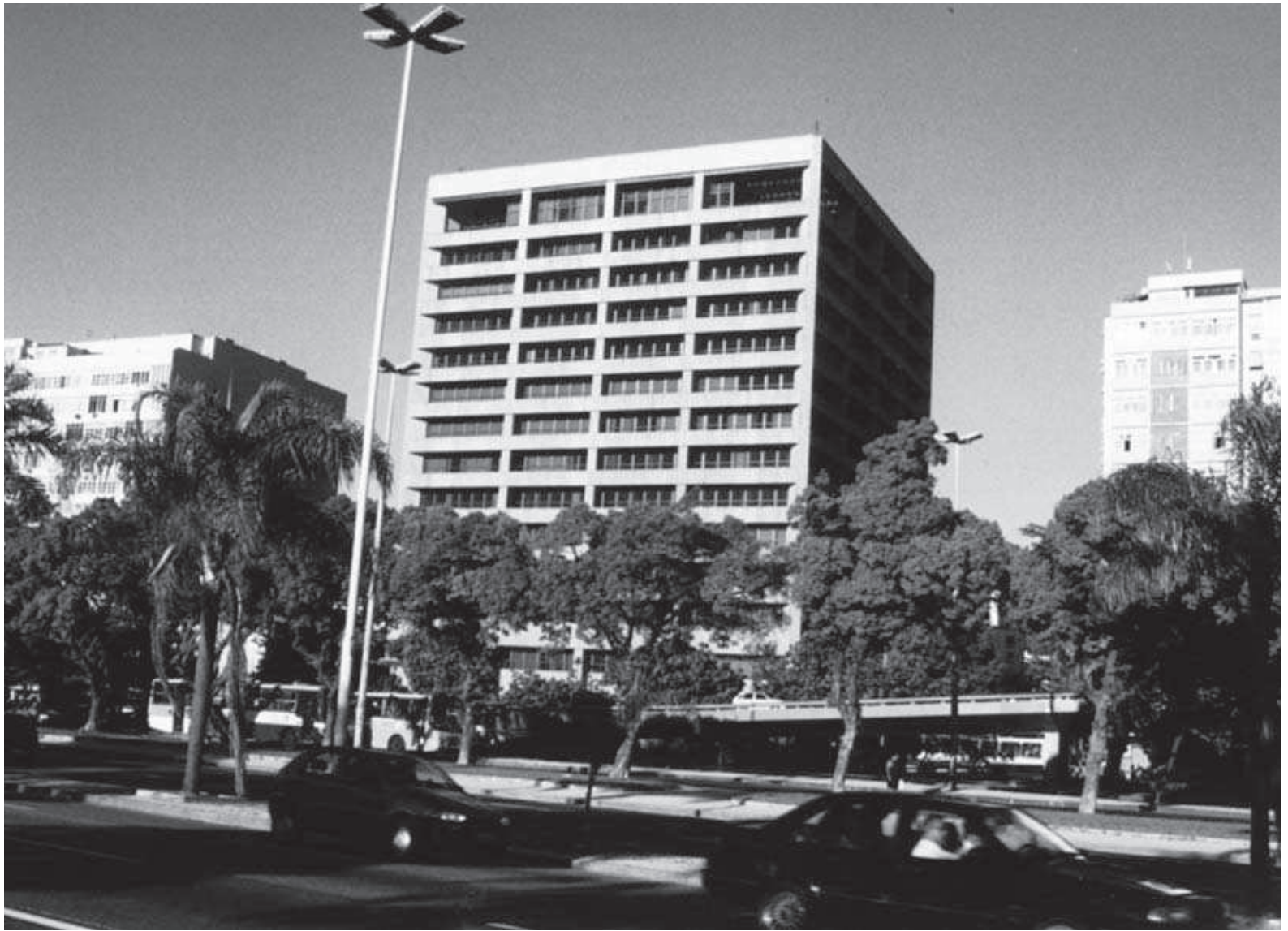

Figura 4: Vista do edifício Caemi, de dois edifícios de moradia bloqueando a vista do Corcovado, campanário da Igreja da Conceição - marco vertical no início do século XX e viaduto em meio à arborização; descompromisso com a paisagem natural e desproporção da massa edificadal

Os quatro primeiros fatores estão relacionados com o olhar profissional de um arquiteto interessado em compreender as conseqüências materiais da intervenção humana no ambiente. Os dois últimos fatores estão relacionados com a possibilidade de aproveitar a experiência acumulada em diversas observações na construção de um instrumento capaz de integrar e ponderar os valores e os significados para os diversos grupos envolvidos com a produção, o consumo e o uso do ambiente construído e a Praia de Botafogo.

\section{O Processo de ocupação da Enseada de Botafogo}

O processo de ocupação da enseada de Botafogo e o acúmulo de objetos "ávidos por atenção", produzidos para atender aos interesses de seus proprietários e projetistas, refletem o descaso histórico com a paisagem natural e evidencia o processo de destruição da beleza da paisagem e do meio ambiente. (Fig. 5)

Apesar de sua configuração ter condicionado seu traçado inicial, hoje é possível observar pelo menos dois princípios de ordenamento (Beguin 1991): (a) substituição dos limites naturais pelos limites técnicos, econômicos e políticos - função de passagem do bairro justifica os aterros de alagadiços e as obras viárias (corte de morro, abertura de túnel, construção de viadutos); perfuração da linha 1 do metrô e a construção em área pública de preservação ambiental (postos de gasolina, restaurantes, clubes e edifício de escritórios); e (b) a densidade histórica da cidade dissolve-se em benefício da banalização do urbano - verticalização e densificação imobiliária, mantendo o parcelamento do solo; liberação da taxa de ocupação e do gabarito; permissão para construir edifício praticamente desprovido de janelas. (Fig.6) 


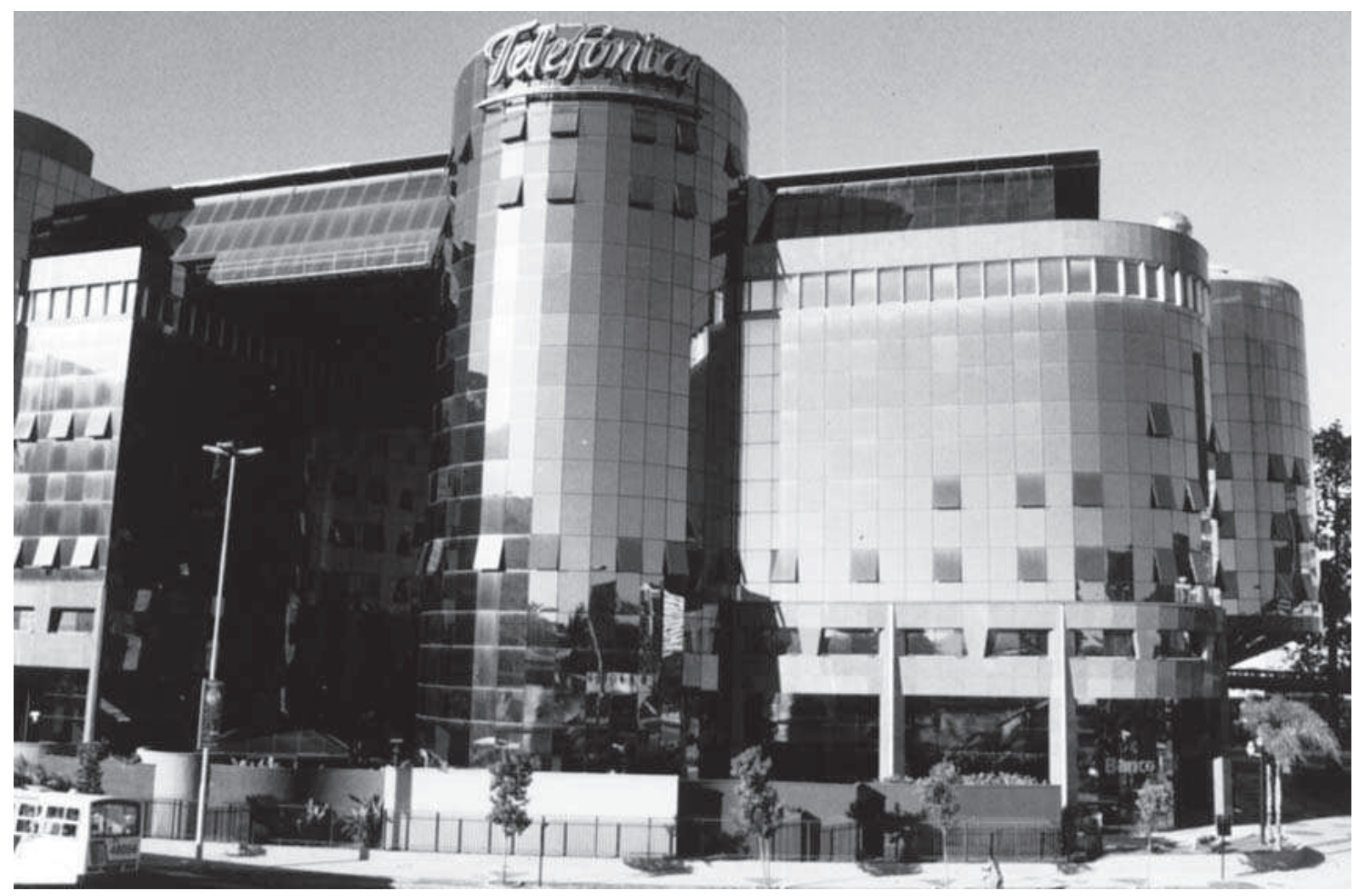

Figura 5: Centro Empresarial Mourisco (2000). Privatização de área pública de proteção ambiental; extravagância formal e de materiais, "ávido por atenção" e casuísmo das autoridades públicas

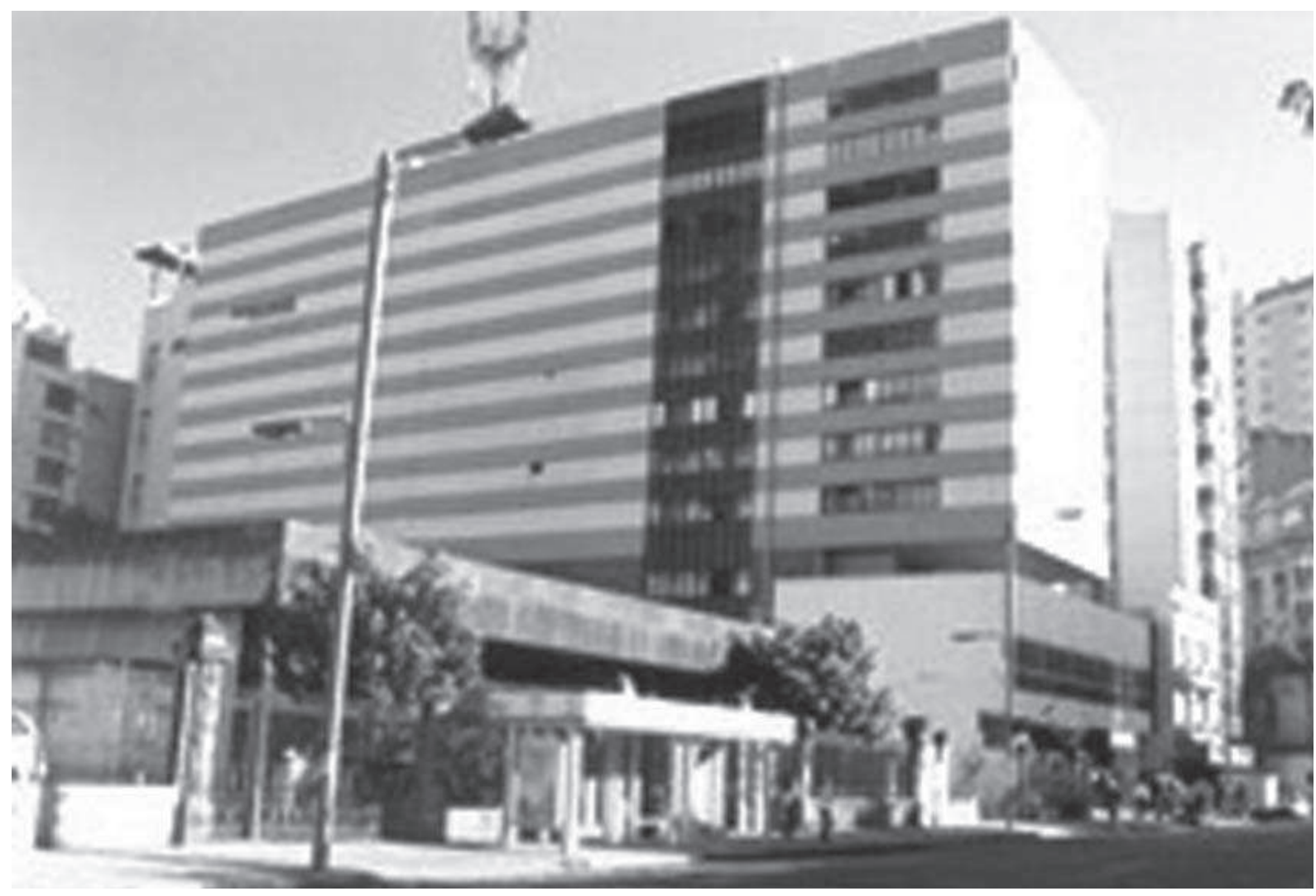

Figura 6: Edifício Telemar (2000) - antiga planta industrial praticamente desprovida de aberturas em meio a um cenário deslumbrante - abrigo de ônibus - obstáculo ao fluxo de pedestres - tendo ao fundo o antigo edifício da livraria da FGV, hoje demolido 
Para Sérgio Santos (1981: 214), a área evidencia que o "poder público não tem senão corroborado tendências 'espontâneas', implementando serviços e infra-estrutura urbana e mesmo regulamentando, onde a iniciativa privada já "criou o fato." O autor explicita a lógica do processo de desenvolvimento da cidade: dependência das soluções técnicas em relação às condições e interesses políticos dos grupos que comandam a Administração Pública que dificulta e/ou impede sua implementação; e ação regulamentadora do Poder Público apenas corrobora a ação da iniciativa privada, principal elemento criador de tendências de transformação do espaço urbano. Neste sentido, Botafogo "mostra os efeitos dessa ação conjugada, ao refletir em seu espaço os efeitos transformadores impostos por sua recriada função de passagem" (S. Santos 1981: 214).

processo de atração das grandes empresas a partir dos anos 70, por sua vez, está diretamente relacionado com a saturação e a valorização da área central da cidade. A velocidade da transformação de Botafogo em "centro especializado de serviços ... [revela a] forma predatória e imediatista com que se consolida e expande o espaço conquistado pela cidade" (S. Santos 1981: 216). As marcas desta urbanização fragmentada podem ser atribuídas à adequação do "saber técnico" aos interesses econômicos dos "donos da cidade" (Niemeyer 1980: 36) e à lógica da "mão invisível" do mercado, sempre com o beneplácito do Estado.

A prevalência da concepção do edifício como obra isolada de seu contexto físico pode ser comparada com a existente entre o monolito do filme 2001 Uma Odisséia no Espaço e os macacos que o observam: sua melhor expressão, a metáfora dos "transatlânticos ancorados nas calçadas das metrópoles" (Musa in Camargo 1989: 84), ilustra o processo de internacionalização característico da produção dos novos edifícios de escritórios.

O edifício da Fundação Getúlio Vargas (1955), exemplar único da proposta de Oscar Niemeyer para construção de "edifícios semelhantes paralelos, eqüidistantes e com a mesma altura, visando à preservação da silhueta das montanhas ao fundo e da paisagem natural circundante" (Xavier et al 1991: 97), que apresenta os seguintes equívocos: embasamento e lâmina do edifício "opacos", desprovidos de "olhos"3 para a via, rompendo a tradicional relação edifício-pedestre; desobediência, pelo próprio autor, do limite de pavimentos recomendado por Niemeyer para os edíficios da orla - fixando para toda a cidade, exceto a Barra da Tijuca, o gabarito máximo de 4 pavimentos (Niemeyer 1980) - para preservar a paisagem natural circundante; desprezo ao clima, ao propor duas cortinas de vidro orientadas para leste e para oeste, condenando os usuários do edifício ao eterno desconforto provocado pelo efeito estufa. (Fig. 7)

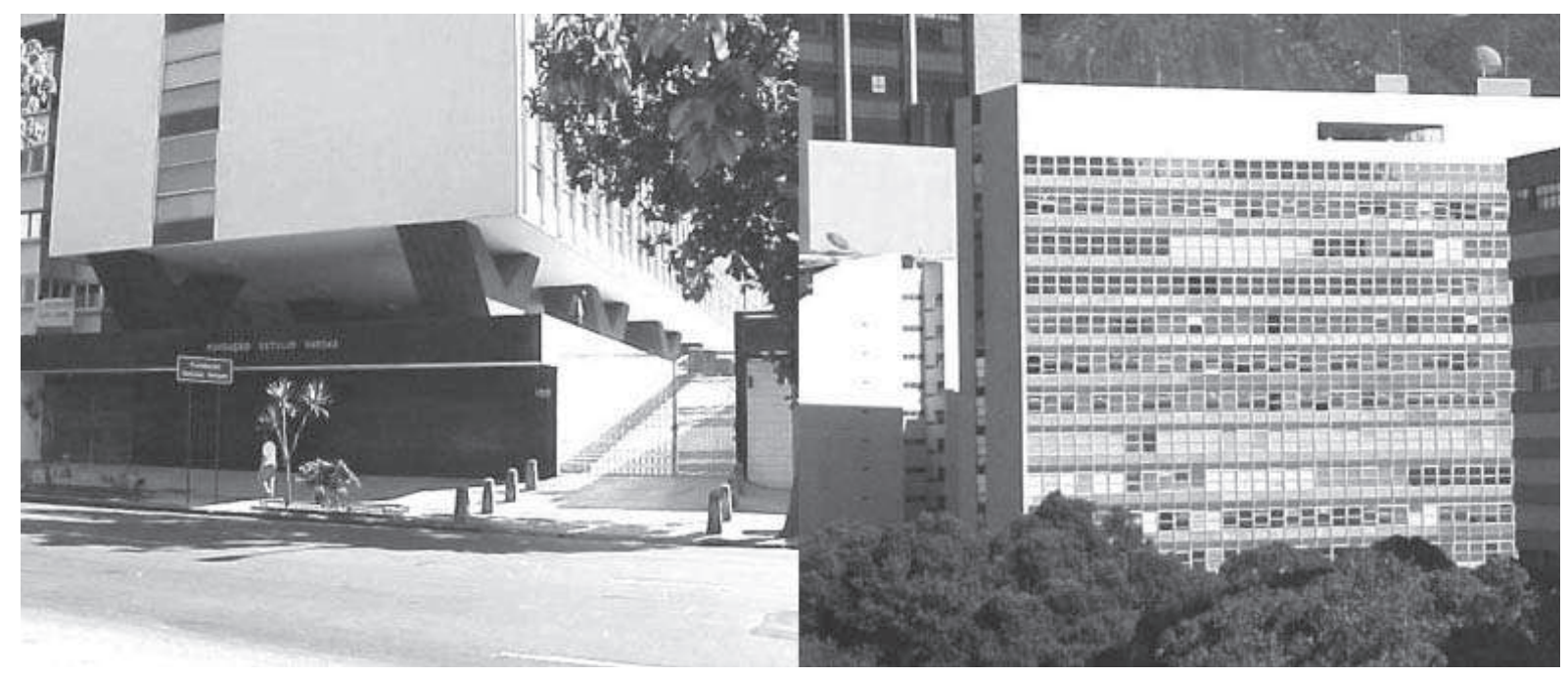

Figura 7: Edifício da Fundação Getúlio Vargas (1999): (a) parede cega de granito preto, hoje vazada para abrigar a Livraria da FGV: (b) parede-coletor solar. 
A segunda concepção é representada pela transposição mimética do Internacional Style e seus edifícios-máquina de trabalhar, localizados, concebidos e ocupados segundo uma lógica de exploração predatória das condições locais e de exclusão das relações sociais que ocorrem em seu entorno: os "transatlânticos na calçada" escolhem o "porto" mais conveniente para que seu seleto grupo de "passageiros" possa usufruir, sem preocupar-se com o impacto ambiental. (Fig. 8)

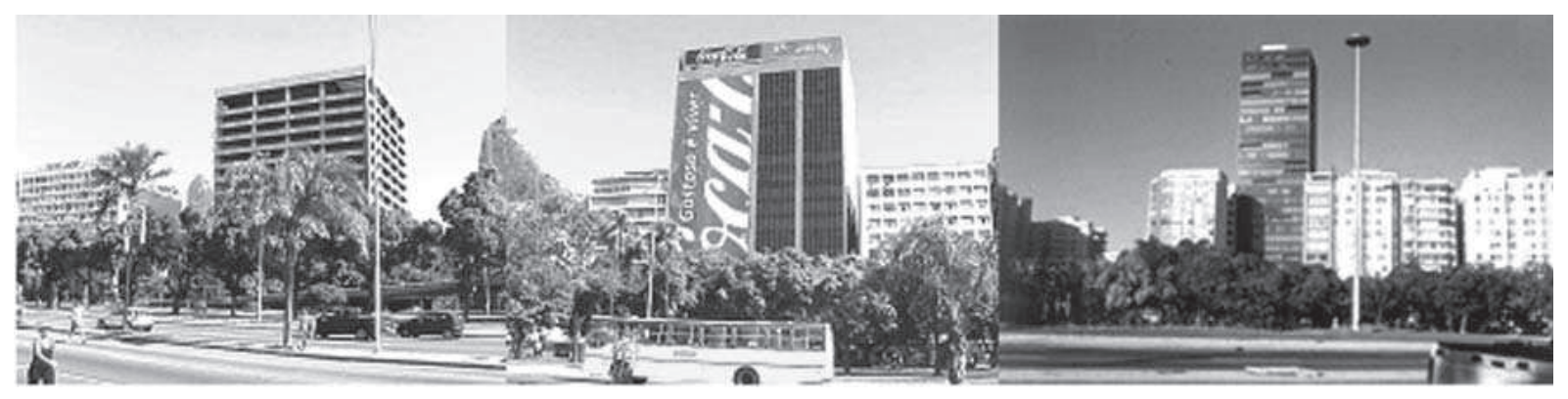

Figura 8: (a) Edifício Caemi; (b) Edifício Coca-Cola/Intelig; (c) Edifício 440 - "Transatlânticos na Calçada"

A terceira concepção é representada pelo casuísmo com que as autoridades públicas tratam sua cidade e pelo tipo de interesses a que ela tem servido: ao privatizar áreas públicas e de preservação ambiental ${ }^{4}$, confirma-se a função corroboradora do Estado em relação aos interesses da iniciativa privada apontada por Sérgio Santos (1981).

Modificar esta visão e esta prática fragmentada não é uma tarefa simples, uma vez que não se trata de uma questão de natureza tecnológica ou de capacidade técnica, mas uma questão de natureza cultural que está cada vez mais sedimentada [com sutis variações] tanto no saber técnico, quanto no gosto de proprietários, ocupantes e cidadãos: na verdade, é uma clara manifestação do "desejo mimético" - termo utilizado por Celso Furtado para explicitar a ilusão de "uma modernidade que nos condena a um mimetismo cultural esterilizante ... [e a] ... obsessão de reproduzir o perfil daqueles que se auto-intitulam desenvolvidos." (in SUNG s/d: 52) - das sociedades capitalistas criado pelo próprio mercado, e que se torna ele próprio o "critério para desejos aceitáveis ou não." (Sung s/d: 55)

Passadas três décadas de explicitação dos equívocos - decorrência da defasagem cultural inerente a todos os períodos de ruptura de valores e paradigmas - ainda persistem as idéias que justificam estes monumentos da irracionalidade: basicamente os investidores escolhem os edifícios, por sua aparência, pela sua localização [e facilidade de acesso], pelo seu custo inicial e pela tecnologia embarcada [sistemas eletrônicos de supervisão e controle nem sempre operacionais]; os produtores não medem seus gastos com a singularidade da aparência e com a novidade tecnológica; pouca importância é dada, por ambos, aos custos operacionais, ao desperdício de energia, à operacionalidade e eficiência dos sistemas prediais; nenhuma importância é dada, por ambos, à adequação climática do envelope, cuja aparência "reflete" o "desejo mimético" que transforma seus proprietários e ocupantes em "personagens de um mundo fantasma ... uma espécie de terceiro mundo, entre o país real em que ... vivem e a comunidade internacional onde imaginam viver" (Costa in Nascimento 1997: 73).

A arquitetura da racionalidade afasta-se cada vez mais de sua razão ética - facilitar e tornar mais confortável a vida do homem sobre a terra - para servir aos interesses do capital imobiliário, ao ego de seus autores e ao "desejo mimético" de seus proprietários e ocupantes. A razão "técni$\mathrm{ca}^{\prime \prime}$ que move sua prática passa a propor e a resolver "desafios" ${ }^{5}$ cujas conseqüências são, em 142 geral, repartidas entre poder público, contribuintes e ocupantes - condenando estes últimos à dependência de dispendiosos equipamentos para garantir seu conforto e bem-estar.

Outras condições que contribuem para a perpetuação dos equívocos, são: a quase inexistência de crítica de arquitetura associada à presença da "louvação" e da manipulação do marketing 
nas matérias que garantem a difícil sobrevivência da imprensa especializada nacional; a prática ingênua e "neutra" da maioria dos pesquisadores que, alheios às modernas estratégias de comunicação, distanciam-se das necessidades e expectativas dos profissionais de projeto, dos construtores e dos cidadãos. Suas descobertas são divulgadas em linguagem incompreensível para o público e, em geral, ficam restritas ao reconhecimento de uns poucos "iniciados".

Estará a humanidade "civilizada" inexoravelmente condenada a viver em um hábitat despersonalizado, desconfortável, cujo cenário se aproxima da sombria Los Angeles do filme Blade Runner ou de "um mundo simulacional que aboliu a distinção entre o real e o imaginário: uma alucinação estetizada e superficial da realidade" (Featherstone 1995), a exemplo do que ocorre na excludente "Barralândia"?

A aceitação do paradigma social e o questionamento sistemático da validade das conquistas da ciência e do avanço da tecnologia - que leva as pessoas a se afastarem de suas tradições culturais e a produzirem as manifestações mais degradadas da arquitetura e da cidade - pode livrar a humanidade desta dura pena, ilustrada por um exercício de observação inspirado na Visão Serial (Cullen 1961), cujas fotos comentadas sugerem um "passeio" bastante pessoal pela enseada de Botafogo.

\section{Considerações finais}

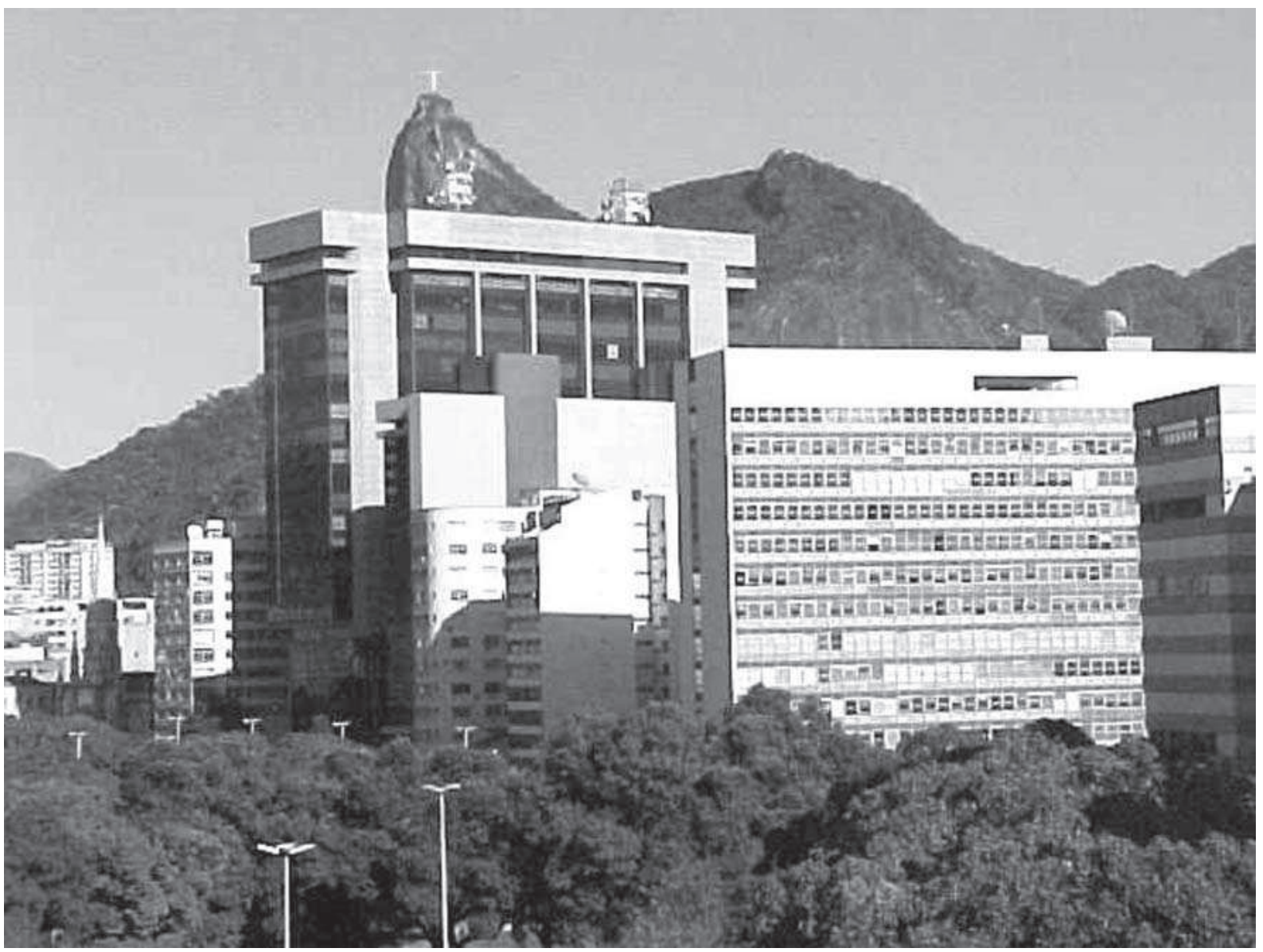

Figura 9: Vista da janela da sala do meu antigo apartamento, no sétimo andar: bloqueio da vista do perfil das montanhas especialmente do Corcovado

O resultado desta experiência vivenciada, associado ao conjunto de análises e comentários compõe uma visão topofílica - permeada de afetos e significados - da enseada de Botafogo, pode ser visto como uma evidência exemplar dos resultados da prevalência da concepção do 
edifício como obra isolada de arquitetura em detrimento de seu relacionamento com o contexto, bem como do casuísmo com que a cidade é tratada pelas autoridades públicas.

A estética destes edifícios e sua propaganda de venda evidenciam o "desejo mimético" do lugar onde seus idealizadores e compradores imaginam ou desejam viver. A metáfora dos "transatlânticos ancorados na calçada" ávidos por atenção pode ser considerada sua mais pura expressão. $O$ resultado desta lógica que despreza o clima e a paisagem local é expresso através da produção de um ambiente construído que funciona como tapume da esplendorosa paisagem natural delineada pelo contorno dos morros circundantes.

O ambiente construído da enseada de Botafogo é um reflexo da esquizofrenia [ou aleatoriedade] da arquitetura da razão técnica e seus "desafios" e evidencia que, se não conseguirmos superar as limitações do paradigma racionalista em prol de um paradigma social complexo, estaremos inexoravelmente condenados a viver em um hábitat despersonalizado, desconfortável e desumano, além de pouco civilizado.

O descaso dos agentes promotores do ambiente contruído - inclusive os arquitetos - com a paisagem natural é tanto (Fig. 9) que mesmo da janela do sétimo andar de um apartamento situado na Praia de Botafogo, se consegue vislumbrar menos de $30 \%$ do principal símbolo urbano da cidade, cotado inclusive para ser considerado uma das maravilhas da humanidade. E o pior é que esta prática tem associada a assinatura do arquiteto brasileiro com maior renome internacional (Edifício da FGV).

A continuar o atual andar da carruagem, e se de fato o perfil da orla for ocupado por espigões cada vez maiores, em breve poderemos estar condenados a ter de pagar para ver o Corcovado, - Morro Dois Irmãos, a Pedra da Gávea e outros marcos naturais deste sítio natural de beleza ímpar. Não é despropositado imaginar que a esta altura, alguns dos nossos "homens bons" já estejam maquinando coisas deste tipo e de como estender suas garras afiadas e insaciáveis com vistas a lucrar com nosso mais precioso bem: o patrimônio natural, que deveria ser eternamente público.

\section{Notas}

(1) Texto adaptado e atualizado de RHEINGANTZ (2000, p. 290-296).

(2) Paula Autran, "Uma relação de amor e medo", O Globo, Rio de Janeiro, 15 de novembro de 1999.

(3) Referência à metáfora utilizada por Jane Jacobs em Morte e vida das grandes cidades (1960).

(4) Os exemplos mais evidentes são: late Clube, piscina do Botafogo, sede do Clube Guanabara, restaurante Sol e Mar e Centro Empresarial Mourisco, cuja concessão do direito de construção, em troca da preservação do PaviIhão Mourisco do Botafogo Futebol e Regatas - a exemplo do tombamento do edifício do Canecão - merece um capítulo à parte no livro negro da história recente da cidade.

(5) Em mais um moderninho: Rio Branco ganha novo prédio "inteligente" (Veja, Rio, 09 de agosto de 1992, p. 19), o autor do projeto do Edifício Manhattan Tower declara: "nunca fizeram um prédio tão alto num terreno tão pequeno, de apenas 726 metros quadrados."

\section{Bibliografia}

AUTRAN, Paula. Uma relação de amor e medo. O Globo, Rio de Janeiro, 15 de novembro de 1999.

BANDEIRA \& ANDRADE. Rio de Janeiro em seus quatrocentos anos. Rio de Janeiro: José Olympio, 1965.

BERNARDES, Lysia. Considerações sobre a região do Rio de Janeiro. In: BERNARDES \& SOARES. Rio de Janeiro: Cidade e região. 3. ed. Rio de Janeiro: Secretaria Municipal de Cultura, p. 71-80, 1995.

CAPRA, Fritiof. Sabedoria incomum. São Paulo: Cultrix, 1991.

A teia da vida. São Paulo: Cultrix, 1997. 
COSTA, Jurandir F. A ética democrática e seus inimigos. In: NASCIMENTO, Elimar P. (Org.) Ética. São Paulo: Garamond, 1997.

CULLEN, Gordon. Paisagem urbana. Lisboa: Edições 70, 1983.

DEL RIO, Vicente. (Org.) Arquitetura: Pesquisa \& projeto. São Paulo: ProEditores/Rio de Janeiro: FAU-UFRJ, 1998.

FEATHERSTONE, Mike. Cultura de consumo e pós-modernismo. São Paulo: Studio Nobel, 1995.

GOMES, Renato Cordeiro. Todas as cidades, a cidade. Rio de Janeiro. Rocco: 1994.

MATURANA, F.; VARELA, F. A árvore do conhecimento. Campinas: Editorial Psy II, 1995.

NIEMEYER, Oscar. Rio. Rio de Janeiro: Avenir Editora, 1980.

PRIGOGINE, I.; STENGERS, J. Entre o tempo e a eternidade. São Paulo: Cia. das Letras, 1992.

A nova aliança: Metamorfose da ciência. 4 ed. Brasília: Editora da UNB, 1997.

SANTOS, Boaventura S. Um discurso sobre as ciências. 7 ed. Lisboa: Afrontamento, 1995a.

SANTOS, A. C.; DEL RIO, V. (Org.). A outra urbanidade: A construção da cidade pös-moderna e o caso da Barra da Tijuca, 1998.

SANTOS, Sergio R. L. dos. Análise da estruturação de bairros do Rio de Janeiro - O caso de Botafogo. 1981. Dissertação (Mestrado em Planejamento Urbano e Regional) - COPPE/UFRJ, Rio de Janeiro, 1981.

SUNG, Jung Mo. Desejo, mercado e religião. 3 ed. Petrópolis: Vozes, s/d.

TUAN, Yi-fu. Topofilia. São Paulo: Difel, 1980. 